\title{
Thai ELF Users' Characteristics of Relative Clauses
}

\author{
Napasri Timyam \\ Associate Professor, Department of Linguistics, Faculty of Humanities, \\ Kasetsart University, Bangkok, Thailand \\ napasri.t@ku.th
}

\begin{abstract}
To build up the empirical description of ELF's morphosyntactic system, this study examines Thai ELF users' characteristics of relative clauses and analyses the causes underlying their use of the construction. Data were taken from the writing of 116 advanced and upper-intermediate English majors at a university in Bangkok. The results indicated that Thai ELF users' relative clauses exhibit preferences for unmarked and explicit structures. Both linguistic and functional causes are responsible for their production of the construction: they form relative clauses full of basic and transparent structures in order to ensure simple and successful communication. The overall results reveal the nature of ELF communication. Although Thai ELF users' relative clauses are associated with some specific patterns, their use of this grammatical construction is governed by general linguistic processes which have been found to operate in the interactions of many groups of ELF speakers, especially at the phonological and pragmatic levels.
\end{abstract}

\section{Keywords}

linguistic processes - morphosyntax - relative clauses - Thai E LF users

\section{Introduction}

Globalisation has brought about worldwide interconnection, which has two enormous effects on the role of English as a common language for international communication. First, it has led to "the decline of the native speaker" 
(Graddol 1999). English is used extensively as a second or foreign language in multilingual contexts in which non-native speakers outnumber native speakers. Second, the interconnection of people has increased the awareness of linguistic diversity, which has coincided with the growth in the description and discussion of English varieties used by non-native speakers (Dewey 2007).

The theoretical approach to English study known as English as a Lingua Franca (ELF) emerged in the second half of the 199os. ELF scholars recognise the spread of English across many regions in terms of its new functions and changes in its linguistic forms, so they have different attitudes towards English study. To capture the nature of lingua franca English, they view ELF speakers as language users in their own right; like native speakers, ELF speakers are not just "recipients" of English, but are "agents" who contribute to the form, spread, and modification of the language (Brutt-Griffler 1998; Seidlhofer 20o1). They can exploit the potential of English by drawing on their multilingual resources and cultural backgrounds, combining and adapting them in a collaborative process of expressing and interpreting meaning, with the focus on the purpose of the talk and successful communication over the linguistic code (Dewey 2014; Jenkins, Cogo, and Dewey 2011; Seidlhofer 2009). In other words, ELF speakers are active language users who can produce a form of English which is different from native speaker norms, with their own emerging strategies and specific features (Rowley-Jolivet 2017).

ELF research concentrates on intelligibility. In international communication, success is mainly determined by the achievement of communication, and greater accuracy does not necessarily mean higher communicative success (Mauranen 2018; Pitzl 2015). Accordingly, economy and communicative effectiveness are usually more important than correctness, strict adherence to grammatical rules, and the use of language as markers of prestige (Breiteneder 2009). Due to such communicative contexts, some general linguistic processes have operated in ELF interactions. These processes such as simplification (replacing complex forms with simple ones), regularisation (making rules general and consistent), accommodation (adjusting some aspects of the language such as an accent to appear more like the style of an interlocutor), and approximation (producing rough equivalents of target elements) also occur in other language contact situations, and they reflect ELF speakers' focus on how to accommodate each other and achieve their intended meaning (Jenkins 20o9; Mauranen 2012, 2018).

Compared to phonological and pragmatic features, research on ELF's morphosyntax has developed more slowly because a reliable description of this 
area usually requires a large amount of data (Jenkins et al. 2011). Among studies on ELF's morphosyntactic system, many have centred on particular word classes and phrasal patterns (e.g., Kirkpatrick 2011; Rowley-Jolivet 2017); there are a few studies on larger units such as grammatical constructions (e.g., Björkman 2008; Ranta 2006). Besides, most detailed studies on ELF's linguistic forms involve speakers from Europe and the outer circle of postcolonial Asian countries (e.g., Breiteneder 2009) while those on the expanding circle of Asian countries are far less common (e.g., Kirkpatrick (2010)'s the Asian Corpus of English Project). Moreover, as Dewey (2014) and Rowley-Jolivet (2017) noted, ELF research has largely dealt with spoken interactions (e.g., Cogo 2010; Mauranen 2007), with a small number of empirical studies on the written form of language (e.g., Ingvarsdóttir and Arnbjörnsdóttir 2013). In fact, innovations and deviations in written language in which users usually have more time to organise and express ideas may reveal interesting implications for ELF communication.

To deal with these limitations of the previous literature, this study investigates one syntactic structure in the writing of advanced and upperintermediate Thai ELF users. As an Asian country in the expanding circle, Thailand does not have a colonisation history and Thai people rely on English mainly for international communication. The study focuses on relative clauses since the English relative clause is known to be structurally diverse, which may lead to various kinds of patterns of use among L2 users. The choice of some particular structures over the alternative variants may reveal the way ELF speakers make use of English to achieve communication. Moreover, although there are quite a few studies on Thai students' relative clauses, most of them are conducted from the viewpoint of second language studies, with the focus on "grammatical errors" (e.g., Phoocharoensil 2014; Phoocharoensil and Simargool 2010); this is different from the ELF perspective, which aims to identify "distinct or deviant features" and interpret the motivation behind those features. The objectives of the study are (1) to examine Thai ELF users' characteristics of relative clauses and (2) to analyse the causes underlying their use of the construction. It is hypothesised that Thai ELF users' relative clauses are associated with some specific patterns owing to linguistic and functional causes, yet their production of this grammatical construction is also governed by general linguistic processes which have been found to operate in the interactions of many groups of ELF speakers, especially at the phonological and pragmatic levels. The results of the study contribute to the empirical description of the linguistic forms of ELF and provide an insight into the linguistic processes that underlie ELF communication. 
The literature review covers two areas: research into the nature of ELF and the formal properties of English relative clauses.

\subsection{Research into the Nature of $\mathrm{ELF}$}

Language contact is a key force of dynamism in language and is one of the most important and most widely recognised engines of language change (Mauranen 2018). When a language travels from one place to another, it encounters new contexts, people, and languages, all of which cause language change (Cogo and Dewey 2006). This is a natural phenomenon that applies to all languages, and it is the condition that has shaped the form of ELF. As English has continuously spread across areas, the backgrounds of its users have been integrated into ELF's character. As a result, ELF's form is heterogeneous; both English and other languages comprise its characteristic features, contributing to the "multilingual nature" of ELF (Jenkins 2017). Many features are specific to a "similect", i.e., a form of ELF shared by speakers with the same non-English L1 background, and other features are more common and can be found in different localities and situations (Mauranen 2012, 2018).

A number of studies have revealed patterns of change and linguistic fluidity as English has been used in lingua franca interactions (Cogo 2015; Dewey 2007; Jenkins et al. 2011). According to the main findings of these studies, ELF is transformed to suit the needs of speakers; its form adapts to an individual situation and may vary in each interaction. In other words, the context of use plays a vital role in ELF communication. In a multilingual setting where English is chosen as a contact language, speakers bring the variety of English they are familiar with (their similect) and employ various strategies to communicate with one another effectively. Accordingly, the use of ELF is conceptualised not as a fixed or specific variety of English, but rather as a function that English performs in international contexts (Ishikawa 2017; Matsuda 2017). For example, Cogo and Dewey (2006) found that the ratio of zero marking to $-s$ form significantly increased when no native speaker was involved in an interaction. Due to the nature of communication, ELF has undergone many kinds of diversity, flexibility, fluidity, and variability, which have made it distinct in all areas, including phonology, pragmatics, and morphosyntax.

A starting point in morphosyntax was made by Seidlhofer (2004), who investigated lexical and grammatical features in ELF interactions. She noticed that there are some deviant lexical and grammatical items that are used systematically and frequently by ELF speakers from a range of first languages without causing communication problems. Examples of these features include zero 
marking of the third person singular present tense -s (e.g., he get), the use of verbs with high semantic generality (e.g., do, have, make), the increase of explicitness (e.g., how long time, yellow colour), the ellipsis of verb complements (e.g., you can borrow), the invariant use of question tags (e.g., isn't it?), and the extension of the relative marker which to include functions traditionally served by who (e.g., the woman which I met). Seidlhofer's list gave direction to research in the area and numerous subsequent studies explored one or more of the listed features in detail (e.g., Cogo and Dewey 2006; Hülmbauer 2013) (Jenkins et al. 2011). These studies have revealed the position of ELF on the continuum of change in comparison to other English varieties in lexical and grammatical features (Mauranen 2018).

In addition to the linguistic form, recent ELF research has turned attention to the causes or functions that are fulfilled by surface features and the underlying processes they reveal (Jenkins 2015). ELF research has attempted to not only identify linguistic features but also account for the underlying significance of the features, i.e., analysing what causes are responsible for the features and what general processes of language evolution they involve (Jenkins et al. 2011; Seidlhofer 2009). There are several empirical studies which have shown that various kinds of linguistic and extra-linguistic factors are responsible for innovations and deviations in ELF's linguistic forms and simplification and regularisation are among the linguistic processes involved in ELF interactions. For example, at the level of phonology, Breiteneder (2009) found that ELF speakers in Europe prefer zero marking not only for usual plural subjects (e.g., they get), but also for third person singular subjects (e.g., he get). Since the information about the number (singular versus plural) in an English sentence is readily derived from the overt subject, the verbal suffix $-s$ becomes a redundant feature. As a result, many European ELF speakers exploit this internal redundancy of the language by using zero marking for both plural and singular subjects in order to establish a simple and regular system.

\subsection{The Formal Properties of English Relative Clauses}

Relative clauses are a type of subordinate clause which gives information about a noun. English relative clauses are introduced by a set of subordinators known as relative markers. Seven $w$ h-words act as relative markers: who, whom, which, whose, where, when, and why. These words occur with different head nouns: who/whom for people, which for things, animals, places, whose for possession, where for places, when for times, and why for reasons. That also serves as a relative marker which can generally be used to replace most $w h$-words except whose. 
Relative markers can be omitted in many circumstances. For example, in Michael rents the apartment [(which) Joe recommended], the relative marker which, which serves as the direct object of the verb, is optional. However, there are four kinds of context which do not allow the omission of relative markers, i.e., when a relative marker functions as the subject, it is preceded by a preposition, it appears as the possessive form whose, and it begins a non-restrictive relative clause, as illustrated respectively in (1).

(1) a. Jim bought a house [which $/{ }^{*} \emptyset$ has two bedrooms].

b. That is the customer [with whom/** with Ø I spoke].

c. This is the girl [whose $/{ }^{*} \emptyset$ brother is a singer].

d. Max, [who/ ${ }^{*} \emptyset$ is my classmate], is going to study in Australia.

A relative clause in English contains a gap whose reference matches the head noun. The position that corresponds to the gap is called the relativised position. For example, in The friend [who_ met me at the restaurant] comes from Tokyo, the relativised position is the subject, and in The teacher was impressed with the essay [which the student wrote_], the relativised position is the direct object. Languages differ in the functional positions that can be relativised. English is one of a few languages that allow relativisation of all positions, such as the subject, direct object, and object of preposition (Keenan and Comrie 1977).

Relative clauses can appear in two major positions. When they give information about a subject, they are placed after the subject and are referred to as centre-embedded relative clauses, e.g., The accident [that happened yesterday] was so terrible. When they describe a complement, they occur in the sentence-final position and are called right-embedded relative clauses, e.g., You should not believe everything [you read online].

Relative clauses are classified into two types: restrictive relative clauses and non-restrictive relative clauses, as illustrated respectively in (2).

(2) a. The police talked to the neighbours [who saw Joe leave].

b. The police talked to the neighbours, [who saw Joe leave].

Semantically, a restrictive relative clause gives important information that restricts the head noun whereas a non-restrictive relative clause provides supplementary information that is not essential but may elaborate on the head noun (Downing and Locke 2006). Based on such interpretations, the relative clause in (2a) restricts the reference of the neighbours; the police talked to 
only those who saw Joe leave. In (2b), instead of specifying a subset of the neighbours, the sentence states that the police talked to all of them, and the non-restrictive relative clause gives additional information about the neighbours - that they all saw Joe leave.

In terms of punctuation, restrictive relative clauses are written with no punctuation while non-restrictive relative clauses are written with commas. As for antecedents, restrictive relatives occur with common nouns whereas non-restrictive relatives accept various types of antecedent, including common nouns (e.g., This hypothesis, [which I tested]), proper nouns (e.g., Edgar Allan Poe, [whose works have inspired many readers]), and clauses (e.g., Those documents were sent late, [which caused delay in our business negotiation]) (Huddleston and Pullum 2005). Among these antecedents, proper nouns can be regarded as typical because they specifically and frequently occur with this type of relative clause.

\section{Methodology}

This study employed a qualitative approach by examining Thai ELF users' characteristics of relative clauses and analysing the causes underlying their use of the construction. The participants and instrument of the study are described as follows.

\subsection{Participants}

Although ELF communication includes users at all proficiency levels, its description should be based on proficient users so that some kinds of patterns can be identified (Cogo and Dewey 2006). Accordingly, the target participants of the study were advanced and upper-intermediate Thai ELF users who had received formal instruction in English for many years. This was to ensure that their characteristics of relative clauses could indicate some patterns of ELF's morphosyntactic system, not sporadic errors of beginning learners.

A purposive sampling method was used to select the participants of the study. All participants were competent and experienced English users who met the following two language criteria. First, they were second-, third-, and fourth- year English-major students at a university in Bangkok, who had practiced the four English skills (listening, speaking, reading, and writing) for many years, especially during their study at the university. Second, they had an average grade of over 3.20 (out of 4) for all English classes taken at the university. In total, 116 participants took part in the study. 


\subsection{Instrument}

All participants were volunteers who attended two sessions of English writing tasks. To make the writing tasks more similar to actual communication which had a purpose and a target group of audience, the researcher explained to them that the purpose of the writing was to practice using English as a means of international communication and to express their opinion on a chosen topic for readers from multilingual backgrounds. The participants were instructed to write clearly and logically to make their message intelligible in international communication. The objective of the writing tasks was to stimulate the participants to produce a kind of naturalistic data in a near-authentic situation about a variety of topics using expressions and structures they had studied or were familiar with.

To ensure that their writing covered a wide range of issues, the two sessions focused on different topics. In the first session, the participants wrote one essay on a casual or less serious topic (e.g., a technological device we cannot live without, a childhood memory). In the second session, they wrote another essay on an academic or more serious topic (e.g., the ASEAN community, capital punishment). The two sessions were held on different days so that the participants could concentrate thoroughly on their writing.

Both writing sessions were conducted in casual special meetings (not regular class meetings) in a classroom during two consecutive weeks. All participants chose a period of time (in the morning from 9.00 to 12.00 or in the afternoon from 13.00 to 16.00) and a day (from Monday to Friday) they were available in each of the two weeks. In each session, the participants were given three sheets of paper. On the first page, they filled in their personal information, such as their name, age, year of study, and average grade in English classes. On the next page, there was an instruction in English to write a two-page essay (about 1,200-1,500 words). They were instructed to write an essay on a casual topic in the first session and another essay on an academic topic in the second session. In each session, a list of six suggested topics was provided. The participants could write about one of the suggested topics or any topic of their interest. In both sessions, the participants did the writing task independently, and most of them finished an essay within two hours.

\subsection{Verification}

All relative clauses produced by the participants were collected and classified based on their structural characteristics. Inter-coder procedure was used to ascertain the reliability of data coding. Twenty percent of the participants' relative clauses were randomly selected and coded by two experts in English 
1. The presence of a relative marker: Is the relative $100 \% \quad 100 \%$ clause introduced by a relative marker?

2. That replacement: For a that relative clause, what wh-marker is replaced by the substitute word that?

3. The relativised position: What is the relativised position of the relative clause?

4. The position of a relative clause: What is the position of the relative clause with respect to the clause having its head noun?

5. The type of a relative clause: Is the relative clause restrictive or non-restrictive?

6. The antecedent of a non-restrictive relative clause: What type of antecedent does the non-restrictive clause modify?

syntax to crosscheck the researcher's classifications. Both experts were English teachers who had taught many courses on English structure and English linguistics to undergraduate students for more than ten years. They were asked to classify the participants' relative clauses in terms of the following characteristics listed in Table 1. They were also given a brief definition and examples for each of the characteristics. For each type of these classifications, the agreement rates between the two experts and the researcher were in excess of $85 \%$. For all items that were coded differently, they were discussed to reach a final agreement.

There were 1,118 relative clauses in the 232 essays of the 116 participants. Most of these relative clauses did not violate grammatical rules but they showed preferences for some particular structures over alternative variants. The characteristics of the participants' relative clauses are divided into five categories, which are presented below. 
TABle 2 The Presence of a Relative Marker

The presence of a relative marker

Clauses with relative markers

Clauses without relative markers

Total
Frequency

$$
\begin{aligned}
& 211(58.45 \%) \\
& 150(41.55 \%) \\
& 361
\end{aligned}
$$

\subsection{The Presence of a Relative Marker}

The majority of the participants' relative clauses began with a relative marker. There were 945 relative clauses that were introduced by a relative marker $(84.53 \%)$. Only 173 clauses were not marked by any wh-word or that $(15.47 \%)$.

To examine the presence of a relative marker more closely, two groups of relative clauses whose relative markers were not optional based on the nativespeaker norms were excluded. The first group included relative clauses that occurred in the four contexts which did not allow the omission of a relative marker, i.e., when a relative marker functioned as the subject of a relative clause, it was preceded by a preposition, it appeared as the possessive form whose, and it began a non-restrictive relative clause. The second group included relative clauses which modified the manner antecedent (the way); this antecedent has been found to occur with null-marker relative clauses so often that they have become like a fixed or idiomatic expression in several English varieties including native-speaker English (e.g., I like the way [ $\emptyset$ they are trying to solve the problem]) (Suárez-Gómez 2015). The results showed that the participants produced a total of 361 relative clauses that were optionally introduced by a relative marker. Among these relative clauses, many of them, i.e., 211 clauses, were explicitly marked by a wh-marker or that (58.45\%) whereas 15 o clauses did not have a relative marker (41.55\%) (see Table 2). Examples of the participants' relative clauses with and without a relative marker are given in (3).

(3) a. I can choose the subjects [which I want to learn]. (Relative clause with a relative marker)

b. Some of activities [ $\varnothing$ I chose] have become my hobbies [ $\varnothing$ I love to do].

(Relative clause with no relative marker) 
TABLE 3 The Choice of Relative Markers

\begin{tabular}{lrlr}
\hline Relative marker & Frequency & Relative marker & Frequency \\
\hline That & $372(33.27 \%)$ & Why & $27(2.42 \%)$ \\
Which & $263(23.52 \%)$ & When & $8(0.72 \%)$ \\
Who & $240(21.47 \%)$ & Whose & $2(0.18 \%)$ \\
Null & $173(15.47 \%)$ & Whom & $1(0.09 \%)$ \\
Where & $32(2.86 \%)$ & Total & 1,118 \\
& & &
\end{tabular}

\subsection{That Replacement}

The participants' relative clauses were introduced by the substitute word that most frequently; 372 relative clauses began with this relative marker (33.27\%). The relative markers which and who were chosen less frequently; there were 263 which relative clauses $(23.52 \%)$ and 240 who relative clauses $(21.47 \%)$. The other relative markers appeared much less often (see Table 3 ). Examples of the participants' choices of relative markers are given in (4).

(4) a. Trash is a big environmental issue [that needs to be fixed]. (The relative marker that)

b. It is the tower [which is full of mysterious stories]. (The relative marker which)

c. It helps them to contact others [who are in different places]. (The relative marker who)

Among the 372 that relative clauses, that was used in 329 clauses as a replacement for which $(88.44 \%)$. In contrast, while there were many human head nouns (i.e., 277 human head nouns in the data), most of them occurred with who, with a small proportion occurring with that (5.38\%). Likewise, that replacing other $w h$-markers was quite rare (see Table 4 ). Examples of the participants' use of that are given in (5). 
TABLE 4 That Replacement

\begin{tabular}{lrll}
\hline $\begin{array}{l}\text { Wh-marker replaced } \\
\text { by that }\end{array}$ & Frequency & $\begin{array}{l}\text { Wh-marker replaced } \\
\text { by } \text { that }\end{array}$ & Frequency \\
\hline Which & $329(88.44 \%)$ & When & $6(1.61 \%)$ \\
Who & $20(5.38 \%)$ & Why & $4(1.07 \%)$ \\
Where & $12(3.23 \%)$ & Who \& which & $1(0.27 \%)$ \\
& & Total & 372 \\
\hline
\end{tabular}

(5) a. The most popular way [that improves English skills] is listening to English music.

(That replacement for which)

b. There are only some psychologists and scholars [that make comments on TV or newspapers when a case of suicide happens], but it will be ignored when the news is not in public interest anymore. (That replacement for who)

\subsection{The Relativised Subject}

The participants mostly produced relative clauses with relativised subjects. In more than half of their clauses, i.e., 711 clauses, the subjects were relativised (63.59\%). Other relativised positions were found much less frequently, such as direct objects (21.29\%) and adjuncts (11.45\%) (see Table 5). Examples of the participants' relativised positions are given in (6). It was interesting to note that one common structure of their subject relative clauses was the passive voice; 79 subject relative clauses had passive verb forms.

(6) a. When I was watching the famous TV series, Game of Thrones, I had some doubt about the word "warg" [which _ was said by a character in the story]. (Subject)

b. With this intention, they are supposed to be able to summarise the major topics or keys [that they have learnt_]. (Direct object)

c. America is the first place [where I experienced drinking alcohol_]. (Adjunct) 
TABLE 5 The Relativised Positions

\begin{tabular}{|c|c|c|c|}
\hline Position & Frequency & Position & Frequency \\
\hline Subject & $711(63.59 \%)$ & Genitive & $2(0.18 \%)$ \\
\hline Direct object & $238(21.29 \%)$ & Subject complement & $2(0.18 \%)$ \\
\hline Adjunct & $128(11.45 \%)$ & $\begin{array}{l}\text { Direct object \& object } \\
\text { of preposition }\end{array}$ & $2(0.18 \%)$ \\
\hline $\begin{array}{l}\text { Object of } \\
\text { preposition }\end{array}$ & $33(2.95 \%)$ & & \\
\hline Indirect object & $2(0.18 \%)$ & Total & 1,118 \\
\hline
\end{tabular}

TABLE 6 The Positions of Relative Clauses

Position

Frequency

Right-embedded relative clauses

In sentence-final position \& followed by

$$
\begin{aligned}
& 784(70.13 \%) \\
& 662(59.21 \%) \& 122 \\
& (10.91 \%) \\
& 334(29.87 \%) \\
& 1,118
\end{aligned}
$$$$
\text { other clauses }
$$

Centre-embedded relative clauses

Total

\subsection{The Right-Embedded Relative Clause}

Many of the participants' relative clauses were right-embedded; 784 relative clauses appeared at the end of the clauses having the head nouns (70.13\%). In contrast, only 334 relative clauses were centre-embedded, put medially in the clauses having the head nouns $(29.87 \%)$. Moreover, for the 784 rightembedded relative clauses, the majority - 662 clauses - also occurred at the end of the sentences $(59.21 \%)$; that is, they were placed in the sentence-final position, with no other following clauses. Only 122 right-embedded relative clauses were followed by one or more other clauses in the sentences (10.91\%) (see Table 6). Examples of the participants' relative clauses in different positions are given in (7). 
(7) a. It also reveals reasons [why Thai youths keep changing their mobile phones].

(Right-embedded relative clause in the sentence-final position)

b. If you are tourists [who love sight-seeing trips], Wat Phra Kaew (or the Temple of the Emerald Buddha) is a very nice place to go. (The English name of the temple added)

(Right-embedded relative clause followed by another clause)

c. One of the literary devices [which are frequently found in plays] is irony.

(Centre-embedded relative clause)

\subsection{The Simple Use of Non-Restrictive Relative Clauses}

The participants' relative clauses were classified into two groups based on their function. Those that gave essential information to restrict the head nouns were identified as restrictive; those that provided additional information to the head nouns whose references were definite and already specified (i.e., common nouns with clear references and proper nouns) were identified as nonrestrictive. Based on this criterion, the participants produced 973 restrictive relative clauses $(87.03 \%)$ and 145 non-restrictive relative clauses $(12.97 \%)$. Since the non-restrictive relative is the more marked type, which occurs less frequently in native-speaker English (Biber, Johansson, Leech, Conrad, and Finegan 1999) and has more distinct characteristics, especially in punctuation and antecedents, all non-restrictive relative clauses were further examined.

The participants' non-restrictive relative clauses were marked with some simple or basic characteristics. In terms of punctuation, only 32 clauses were written with commas $(22.07 \%)$ whereas the commas in 113 clauses were miss$\operatorname{ing}(77 \cdot 93 \%)$. As for antecedents, there were 65 proper nouns, which are considered as the typical antecedent of the non-restrictive relative clause $(44.83 \%)$.

TABLE $7 \quad$ Non-Restrictive Relative Clauses

Punctuation Antecedent

\begin{tabular}{lcll}
\hline No comma & $113(77.93 \%)$ & Proper noun & $65(44.83 \%)$ \\
Comma & $32(22.07 \%)$ & Common noun & $44(30.34 \%)$ \\
Total & 145 & Clause & $36(24.83 \%)$ \\
& & Total & 145
\end{tabular}


Other types of antecedents occurred much less often (see Table 7). Examples of the participants' use of non-restrictive relative clauses are given in (8)-(9).

(8) a. You should adopt the "4Ts" idea [which consists of Text, Team, Tool and Target].

(Non-restrictive relative clause with no comma)

b. In this chapter, Ichigo, the main character, is developing to a greater power hero, but he has to fight against the hollow Ichigo, [who is the dark side of his mind].

(Non-restrictive relative clause with a comma)

(9) a. The main character of the story is Alice [who is a girl with a lot of imagination and curiosity].

(Proper noun antecedent)

b. In conclusion, you will become a successful English-major student of the Faculty of Humanities definitely if you follow the aforementioned instructions [which are being responsible, developing yourself continually, and being self-disciplined]. (Common noun antecedent)

c. They drink alcohol before or while driving [which make them drive dangerously].

(Clausal antecedent)

Based on the overall results above, we can make general statements about Thai ELF users' characteristics of relative clauses and analyse the underlying causes as follows. Thai ELF users at the advanced and upper-intermediate levels tend to produce relative clauses which exhibit preferences for some particular structural patterns over alternative variants. Their characteristics of relative clauses probably result from both linguistic and functional causes, which are explained in detail as follows.

\subsection{Linguistic Causes}

The results suggest that linguistic causes play a vital role in Thai ELF users' patterns of relative clauses. English relative clauses are known to be structurally diverse; there are many possible structures to form relative clauses. However, 
Thai ELF users do not make use of all of the possible syntactic complexities. They are more likely to produce relative clauses that are made up of the most basic or unmarked characteristics while complicated or difficult structures are used much less often. The basic and simple characteristics associated with Thai ELF users' relative clauses include (1) the relative marker that, (2) the relativised subject, and (3) the simple use of non-restrictive relative clauses.

The first basic and simple characteristic of Thai ELF users' relative clauses involves the choice of relative markers. English has several relative markers, including seven $w h$-words and that. Although that is preferable in informal contexts, it is prevalent in a variety of registers because it acts like a substitute subordinator or an invariant marker which can be used in place of most wh-relative markers and accepts different kinds of head noun (Biber et al. 1999). Thus, that can be regarded as the typical or basic marker of relative clauses. Thai ELF users choose that much more often than who and which, and the uses of the other $w h$-markers are even much less common. In other words, Thai ELF users prefer to begin relative clauses with that, which is the most typical and basic relative marker. It is worth noting that this preference for the marker that is different from native-speaker English, in which wh-markers are considered more formal and tend to be used more often in written texts, especially in academic writing (Biber et al. 1999).

The second basic and simple characteristic found in Thai ELF users' relative clauses is concerned with relativisation. Keenan and Comrie (1977) posited the following Noun Phrase Accessibility Hierarchy (NPAH) for the relativisability of grammatical functions of head noun phrases:

\footnotetext{
Subject $>$ Direct object $>$ Indirect object $>$ Oblique $>$ Genitive $>$ Object of comparison

(THE SYMBOL > MEANS BEING MORE ACCESSIBLE TO RELATIVISATION AND THE TERM “OBLIQUE” INCLUDES OBJECTS OF PREPOSITIONS AND ADJUNCTS.)
}

According to the NPAH, the subject is the most accessible noun phrase, or the least marked position for relativisation; the direct object is the second least marked position, and so on. The NPAH also reflects the relative ease of relativisation; higher positions are easier to produce than lower ones. Relative clauses in English are known to comply with this typological markedness; all functional positions can be relativised and subject relatives are the most common. Thai ELF users' form of relative clauses is also generally consistent with this universal hierarchy. What is distinct is that the majority of their relative clauses are subject relatives whereas the relativisation of other positions is far 
less frequent. In other words, the degree of difficulty in relativisability affects Thai ELF users' relative clauses. They tend to produce relative clauses with the least marked relativised position, i.e., the subject. Moreover, many of their subject relative clauses have passive verbs. One reason for the passive preference is probably because Thai ELF users find it easier to change a verb form into the passive voice than to produce a relative clause with other relativised positions.

The last basic and simple characteristic of Thai ELF users' relative clauses is shown in the way they produce non-restrictive relative clauses. In nativespeaker English, non-restrictive relative clauses are marked with punctuation - usually commas - to imply that the information they express is additional to the main clause content (Downing and Locke 20o6). However, Thai ELF users do not pay much attention to this grammatical rule; they ignore or probably do not know this difference between the two types of relative clause and simply write non-restrictive relative clauses with no comma. Moreover, they prefer to use non-restrictive relative clauses with proper nouns, which - based on their specific and frequent co-occurrences - are the typical and basic kind of antecedent.

\subsection{Functional Causes}

In addition, the results of the study suggest that Thai ELF users' characteristics of relative clauses also result from functional causes. Even in the written form of English in which they have time to organise and express ideas, Thai ELF users seem to focus on function, instead of form. They give priority to a transparent structure that is easy to understand and can get a message across. As a result, their relative clauses are marked by some characteristics which serve to increase explicitness and ensure successful communication. The communicative or functional characteristics associated with Thai ELF users' relative clauses include (1) the explicit relative marker, (2) the relative marker who, and (3) the right-embedded relative clause.

The first communicative characteristic of Thai ELF users' relative clauses is the presence of a relative marker. Relative clauses often begin with a relative marker, or they may appear as the null-marker structure. The addition of a relative marker in front of a relative clause plays a major role not only in syntactic structure, but also in communication. A relative marker helps indicate the boundary of a relative clause; it clearly separates the relative clause from the main clause and makes the structure of the entire sentence transparent and easier to understand. Thai ELF users' relative clauses often begin with a relative marker. That is, they are likely to produce a relative clause that is structurally transparent, with a relative marker to demarcate the relative clause and facilitate sentence processing. 
The second functional characteristic involves the relative marker who. Most Thai ELF users' relative clauses describing human head nouns begin with who, while only a small number are introduced by the substitute word that. The infrequent that replacement for who is probably due to the clear meaning of this wh-relative marker. Given that the choice of who implies that the head noun in question is animate, particularly a human (Downing and Locke 2006), its meaning is more specific than which or that, which can refer to different kinds of head noun. Therefore, by beginning a relative clause with who, Thai ELF users can increase explicitness in the semantic category of the head noun being described. In other words, the use of who suggests that the relative clause that follows is going to give information about a particular human head noun.

The third functional characteristic is the position of a relative clause, which affects the ease or difficulty of processing. According to Kuno's (1974) Perceptual Difficulty Hypothesis (PDH), due to the limited capacity of the human memory to retain temporary information, some arrangements of sentence constituents are perceptually easier or more difficult to process than others. A sentence with a centre-embedded relative clause is said to interrupt the structure and processing of the main clause; placing the relative clause after the subject noun separates the subject and the predicate, making the structure of the main clause interrupted and perceptually more difficult to process than one with a right-embedded relative clause. As a result, Thai ELF users prefer right-embedded relative clauses that do not break the structure of the main clause and cause the processing interruption. Moreover, Thai ELF users tend to place right-embedded relative clauses at the end of sentences, which is the

TABLE 8 Summary of Thai ELF Users' Relative Clauses

\section{Pattern Cause}

Structures that Linguistic causes: Preferences for basic and simple are basic and structures over complicated and difficult ones simple

1) The relative marker that

2) The relativised subject

3) The simple use of non-restrictive relative clauses

Structures Functional causes: Increased explicitness and efficiency of that are clear communication

and easy to 1) The explicit relative marker

understand 2) The relative marker who

3) The right-embedded relative clause 
perceptually easiest position to process because it does not break the structure of the main clause and also of the entire sentence.

The characteristics of Thai ELF users' relative clauses and the possible causes that underlie their use of the construction are summarised in Table 8.

\section{Discussion and Conclusion}

In ELF research, the description of form is not only carried out to determine features, but also aims to reveal general linguistic processes underlying the surface-level features as ELF speakers collaboratively engage in international communication, negotiate meaning, and adjust expectations on all linguistic levels (Cogo 2012; Hülmbauer, Böhringer and Seidlhofer 2008; Jenkins 2015). It has been observed that ELF speakers tend to shape English in a similar direction which establishes a simpler and more regular system of the language (Breiteneder 2009; Jenkins et al. 2011). There are some kinds of general linguistic processes which guide the interactions of ELF users across lingua-cultural backgrounds, especially at the phonological and pragmatic levels, and these processes are mainly intended to facilitate communication.

The study on Thai ELF users' production of relative clauses demonstrates that three such linguistic processes also underlie ELF's morphosyntactic system, namely simplification, explicitness, and regularisation. As Dewey (2007) stated, these general processes do not simply give rise to linguistic innovation, but they are also regarded as important characteristics of ELF, which contribute to simplicity and effectiveness in communication.

The first process that is revealed in Thai ELF users' production of relative clauses is simplification. This process is regarded as an efficient means of international communication (Hülmbauer et al. 2008). Complex forms are replaced by simple forms, and complex rules are simplified or avoided in ELF interactions. Relative clauses in English are structurally diverse and can be formed by various kinds of structural patterns, but Thai ELF users do not make use of all of the possibilities of syntactic complexity. They usually produce relative clauses that are made up of the most basic or simple characteristics. For example, while English allows all relativised positions, Thai ELF users largely produce a relativised subject, which is known to be the most accessible and simplest position for relativisation. Likewise, they do not differentiate restrictive and non-restrictive relative clauses by commas; they ignore or are not aware of this punctuation rule and simply write the two types of relative clause with no comma. 
The second process which can be observed in Thai ELF users' production of relative clauses is explicitness. This process may not involve speakers' conscious decisions, but it is a natural tendency to enhance salience for effective communication (Dewey 2007). In order to achieve clarity, ELF speakers depend on various kinds of explicitness strategies (Cogo 2015). For example, they insert extra or redundant words, repeat words, or choose meaningful words to ensure clarity of conversation. In the case of Thai ELF users, they are likely to produce relative clauses with structures that are transparent and easy to understand in order to add to the clarity and explicitness of this grammatical construction. For example, Thai ELF users usually begin relative clauses with relative markers, which help separate the relative clauses from the main clauses and make the structure of the entire sentence more transparent. Moreover, they generally use human head nouns with the more semantically specific relative marker who, instead of the general invariant marker that, in order to imply that the head noun that is going to be described is a human.

The third process that is evident in Thai ELF users' production of relative clauses is regularisation. Rules are often regularised to be more consistent and to avoid exceptional forms (Breiteneder 2009). The creation of many new word forms in ELF is motivated by the process of regularisation by means of analogy, such as the addition of the plural suffix -s to uncountable or irregular nouns (Hülmbauer 2013). At the sentence level, this process may occur as the repeated use of certain structures, resulting in the more limited form of a grammatical construction. Thai ELF users regularise many grammatical rules of relative clauses; they do not try to make use of all of the diverse structures that are available but tend to choose only the ones that are simple, explicit, and easy to understand. By overusing these kinds of structural patterns, Thai ELF users establish a simpler and more regular system of producing English relative clauses.

In conclusion, this study examines the characteristics of Thai ELF users' relative clauses and analyses the causes that underlie the use of the construction. The results indicate that Thai ELF users' relative clauses exhibit preferences for some particular structures over alternative variants; many of their relative clauses are made up of the most basic or unmarked characteristics and also structures that are clear and easy to understand. The analysis of the results suggests that both linguistic and functional causes are responsible for their use of the construction; Thai ELF users tend to produce relative clauses full of structures that are basic, transparent, and easy to understand in order to ensure simple and successful communication. However, it is important to note that this does not imply that Thai ELF users' relative clauses are idiosyncratic and totally different from those of other groups of ELF speakers. In fact, some 
of their distinct structures, particularly the relativised subject and the rightembedded relative clause, have been explored extensively in the literature of second language acquisition (SLA) and they have also been found to be used frequently by various groups of L2 speakers (e.g., Izumi 2003; O'Grady 1999).

Taking all of the results into the ELF perspective, it can be said that the forms of relative clauses in the context of Thai ELF users (i.e., the Thai-based similect) reveal one universal mechanism in ELF communication that operates at all linguistic levels. A number of ELF studies, especially at the phonological and pragmatic levels, have shown that innovations and deviations in the interactions of many groups of ELF speakers are governed by some general linguistic processes that reflect the motivation to use and shape the language for the purpose of intelligibility and communicative efficiency (e.g., Björkman 2008; Breiteneder 2009). Likewise, the study of Thai ELF users' relative clauses indicates that the same kinds of linguistic processes often found to operate in ELF pronunciation patterns and pragmatic strategies also play a role in the use of grammatical constructions. Thai ELF users' production of relative clauses is also motivated by similar processes, including simplification, explicitness, and regularisation, which are meant for a simple and successful form of communication.

The overall results of the study of Thai ELF users' characteristics of relative clauses have pedagogical implications. First, the results suggest that form and function are both important in language study. It is helpful to explain to students the syntactic and functional properties associated with a particular construction. For example, a relative marker can be presented as a word that not only begins a relative clause but also serves to make the structure of the relative clause more transparent by clearly separating the relative clause from the main clause. Likewise, it is useful to point out to students that the position of a relative clause may affect sentence processing; putting a very long relative clause at the end of a sentence (i.e., a right-embedded relative clause) helps to facilitate the comprehension of the whole sentence. With a function-based approach, learners will know the major syntactic and functional properties of a construction and will be able to produce the construction more effectively, which will lead to successful communication. In addition, English learners should be taught to be aware of language varieties. When English is used as a lingua franca, communicative success is mainly determined by mutual intelligibility, and differences from native-speaker norms can be expected to appear in all areas - phonology, pragmatics, and morphosyntax. Therefore, it is important for learners to recognise the new forms and functions of lingua franca English and accept different varieties of global Englishes. 
The study of Thai ELF users' characteristics of relative clauses has some limitations. First, the analysis of the results of the study was based on the participants' writing. If this was supplemented with an interview with a group of the participants, it would provide more conclusive evidence, particularly regarding the causes underlying their use of the construction. Moreover, since the data of the study were drawn from the participants' essays, they could not truly represent the actual use of ELF in international contexts. Future studies on the written form of ELF morphosyntax that include both written texts and in-depth interviews as well as elicit data from several ELF settings should provide better insight into ELF communication.

\section{Acknowledgement}

This work was supported by the research fund of the Department of Foreign Languages, Faculty of Humanities, Kasetsart University.

\section{References}

Biber, Douglas, Stig Johansson, Geoffrey Leech, Susan Conrad, and Edward Finegan. 1999. Longman Grammar of Spoken and Written English. Harlow: Longman.

Björkman, Beyza. 2008. "English as the Lingua Franca of Engineering: The Morphosyntax of Academic Speech Events." Nordic Journal of English Studies 7(3): 103-122.

Breiteneder, Angelika. 20o9. "English as a Lingua Franca in Europe: An Empirical Perspective." World Englishes 28(2): 256-269.

Brutt-Griffler, Janina. 1998. "Conceptual Questions in English as a World Language: Taking Up an Issue." World Englishes 17(3): 381-392.

Cogo, Alessia. 2010. "Strategic Use and Perceptions of English as a Lingua Franca." Poznan Studies in Contemporary Linguistics 46(3): 295-312.

Cogo, Alessia. 2012. "English as a Lingua Franca: Concepts, Use, and Implications." ELT Journal 66(1): 97-105.

Cogo, Alessia. 2015. "English as a Lingua Franca: Descriptions, Domains, and Applications." In International Perspectives on English as a Lingua Franca: Pedagogical Insights, edited by Hugo Bowles and Alessia Cogo, 1-12. Basingstoke: Palgrave Macmillan.

Cogo, Alessia, and Martin Dewey. 20o6. "Efficiency in ELF Communication: From Pragmatic Motives to Lexico-Grammatical Innovation." Nordic Journal of English Studies 5(2): 59-93. 
Dewey, Martin. 2007. "English as a Lingua Franca and Globalisation: An Interconnected Perspective." International Journal of Applied Linguistics 17(3):332-354.

Dewey, Martin. 2014. "Pedagogic Criticality and English as a Lingua Franca." Journal of the Spanish Association of Anglo-American Studies 36(2): 11-30.

Downing, Angela, and Philip Locke. 20o6. English Grammar: A University Course. 2nd edition. New York: Routledge.

Graddol, David. 1999. "The Decline of the Native Speaker." In English in a Changing World: AILA Review 13, edited by David Graddol and Ulrike H. Meinhof, 57-68. Oxford, UK: AILA.

Huddleston, Rodney, and Geoffrey K. Pullum. 2005. A Student's Introduction to English Grammar. Cambridge: Cambridge University Press.

Hülmbauer, Cornelia. 2013. "From Within and Without: The Virtual and the Plurilingual in ELF." Journal of English as a Lingua Franca 2(1): 47-73.

Hülmbauer, Cornelia, Heike Böhringer, and Barbara Seidlhofer. 2008. "Introducing English as a Lingua Franca (ELF): Precursor and Partner in Intercultural Communication." Synergies Europe 3(9): 25-36.

Ingvarsdóttir, Hafdís, and Birna Arnbjörnsdóttir. 2013. "ELF and Academic Writing: A Perspective from the Expanding Circle." Journal of English as a Lingua Franca 2(1): 123-145.

Ishikawa, Tomokazu. 2017. "Conceptualising English as a Global Contact Language." Englishes in Practice 4(2): 31-49.

Izumi, Shinichi. 2003. "Processing Difficulty in Comprehension and Production of Relative Clauses by Learners of English as a Second Language." Language Learning $53(2): 285^{-323}$.

Jenkins, Jennifer. 20o9. "English as a Lingua Franca: Interpretations and Attitudes." World Englishes 28(2): 200-207.

Jenkins, Jennifer. 2015. "Repositioning English and Multilingualism in English as a Lingua Franca." Englishes in Practice 2(3): 49-85.

Jenkins, Jennifer. 2017. “The Future of English as a Lingua Franca?” In The Routledge Handbook of English as a Lingua Franca, edited by Jennifer Jenkins, Will Baker, and Martin Dewey, 594-6o5. London: Routledge.

Jenkins, Jennifer, Alessia Cogo, and Martin Dewey. 2011. "State-of-the-Art Article: Review of Developments in Research into English as a Lingua Franca." Language Teaching 44(3): 281-315.

Keenan, Edward, and Bernard Comrie. 1977. "Noun Phrase Accessibility and Universal Grammar." Linguistic Inquiry 8(1): 63-99.

Kirkpatrick, Andy. 2010. "Researching English as a Lingua Franca in Asia: The Asian Corpus of English (ACE) Project." Asian Englishes 13(1): 4-18.

Kirkpatrick, Andy. 2011. "English as an Asian Lingua Franca and the Multilingual Model of ELT." Language Teaching 44(2): 212-224. 
Kuno, Susumnu. 1974. "The Position of Relative Clauses and Conjunctions." Linguistic Inquiry 5(1): 117-136.

Matsuda, Aya (ed.). 2017. Preparing Teachers to Teach English as an International Language. Bristol: Multilingual Matters.

Mauranen, Anna. 2007. "Discourse Reflexivity and International Speakers - How is it Used in English as a Lingua Franca?" Jezik in Slovstvo 52(3-4):1-19.

Mauranen, Anna. 2012. Exploring ELF. Cambridge: Cambridge University Press.

Mauranen, Anna. 2018. "Second Language Acquisition, World Englishes, and English as a Lingua Franca (ELF)." World Englishes 37(1): 106-119.

O'Grady, William. 1999. "Toward a New Nativism." Studies in Second Language Acquisition 21(4): 621-633.

Phoocharoensil, Supakorn. 2014. "Errors on the Relative Marker WHERE: Evidence from an E FL Learner Corpus.” ${ }_{3}$ L: The Southeast Asian Journal of English Language Studies 2O(1): 1-20.

Phoocharoensil, Supakorn, and Nirada Simargool. 2010. "English Relativisation and Learners' Problems." Pan-Pacific Association of Applied Linguistics 14(1): 109-129.

Pitzl, Marie-Luise. 2015. "Understanding and Misunderstanding in the Common European Framework of Reference: What we can Learn from Research on BELF and Intercultural Communication." Journal of English as a Lingua Franca 4(1): 91-124.

Ranta, Elina. 2006. "The "Attractive" Progressive - Why Use the -ing Form in English as a Lingua Franca?" Nordic Journal of English Studies 5(2): 95-116.

Rowley-Jolivet, Elizabeth. 2017. "English as a Lingua Franca in Research Articles: The SciELF Corpus." ASp 71: 145-158.

Seidlhofer, Barbara. 2001. "Closing a Conceptual Gap: The Case for a Description of English as a Lingua Franca." International Journal of Applied Linguistics 11(2):133-158.

Seidlhofer, Barbara. 2004. "Research Perspectives on Teaching English as a Lingua Franca." Annual Review of Applied Linguistics 24(1): 209-239.

Seidlhofer, Barbara. 2009. "Common Ground and Different Realities: World Englishes and English as a Lingua Franca." World Englishes 28(2): 236-245.

Suárez-Gómez, Cristina. 2015. "Adverbial Relative Clauses in World Englishes." World Englishes 34(4): 620-635. 